wThe submitted manuscript has been authored by a contractol The DE-AC05of the U.S. govecolingly, the U.S. Government retains a 960R22464. Accordingly, the U.S. Govblish or reproduce the nonexclusive, royalty-free license to publish or reproduce the published form of this contribution for U.S. Government purposes."

\title{
INTERFACE MODIFICATION DURING OXIDATION OF A GLASS-CERAMIC MATRIX / SiC FIBRE COMPOSITE.
}

A.M. Daniel, A. Martín-Meizoso, CEIT, $\mathrm{P}^{0}$ de Manuel Lardizabal 15, 20009 San Sebastian, Spain; K.P. Plucknett, D.N. Braski. Oak Ridge National Laboratory, Oak Ridge, TN 37831-6068.

\section{ABSTRACT}

Oxidation heat treatments between $375^{\circ} \mathrm{C}$ and $600^{\circ} \mathrm{C}$ for 100 hours in air, have been performed on the calcium aluminosilicate glass-ceramic matrix / SiC fibre reinforced composite CAS/Nicalon (manufactured by Corning, USA). Using a commercial nano-indentation system to perform fibre push-down tests, the fibre-matrix interfacial debond fracture surface energy $\left(G_{i}\right)$ and frictional shear stress $(\tau)$ have been determined. Modification of interface properties, compared to the asfabricated material, was observed at heat treatment temperatures as low as $375^{\circ} \mathrm{C}$, where a significant drop in $\mathrm{G}_{i}$ and an increase in $\tau$ were recorded. With $450^{\circ} \mathrm{C}, 525^{\circ} \mathrm{C}$ and $600^{\circ} \mathrm{C}$ heat treatments, an increase in $\mathrm{G}_{i}$ but a dramatic increase in $\tau$ were recorded. Under four-point flexure testing, the as fabricated and the $375^{\circ} \mathrm{C}$ heat treated materials displayed tough, composite behaviour with extensive fibre pull out, but at $\geq 450^{\circ} \mathrm{C}$, brittle failure with minimal fibre pull out, was observed. This transition from tough mechanical response to one of brittleness is due to the large increase in $\tau$ reducing fibre pull out to a minimum and therefore reducing the total required work of fracture. The large increases in $\tau$ and $G_{i}$ have been attributed to the oxidative removal of the lubricating, carbon interface and the compressive residual stresses across the interface.

\section{INTRODUCTION}

Originally aimed at heat engine applications at temperatures up to $1200^{\circ} \mathrm{C}$, glass ceramic matrix/SiC fibre reinforced composites have not proved to be suitable component materiais due to oxidation of their carbon rich, fibre-matrix interface which is often formed during processing. CMC systems such as CAS/Nicalon, BMAS/Tyranno, LAS/Nicalon and MAS/Nicalon have been studied after applying heat treatments at temperatures up to $1200^{\circ} \mathrm{C}$, in air, for times varying from 4 to over 500 hours [1-6]. The oxidation reactions occurring at the carbon rich interface are ;

$\mathrm{C}+1 / 2 \mathrm{O}_{2} \rightarrow \mathrm{CO}$

$\mathrm{C}+\mathrm{O}_{2} \rightarrow \mathrm{CO}_{2}$

at temperatures above approximately $400^{\circ} \mathrm{C}$, followed, at temperatures higher than $600^{\circ} \mathrm{C}$, by the oxidation of the fibre surface, forming silica across the interface ;

$\mathrm{SiC}+2 \mathrm{O}_{2} \rightarrow \mathrm{SiO}_{2}+\mathrm{CO}_{2}$ 


\section{DISCLAIMER}

Portions of this document may be illegible in electronic image products. Images are produced from the best available original document. 
$\mathrm{SiC}+3 / 2 \mathrm{O}_{2} \rightarrow \mathrm{SiO}_{2}+\mathrm{CO}$

This silica "bridge" strongly bonds fibre to matrix and causes brittle behaviour of the composite $[1-6]$.

Interface properties of debond fracture surface energy $G_{i}$ and frictional shear stress $\tau$ have previously been measured for many heat treated glass ceramic matrix composite systems, using the fibre push-down test [1-4]. At temperatures between $600^{\circ} \mathrm{C}$ and $800^{\circ} \mathrm{C}$ the bonding of fibre to matrix by the silica bridge is demonstrated by a large increase in $G_{i}$ (compared to the as-fabricated specimen) and intermittent, localised bridging along the length of the interface is indicated by the large standard deviations in both $G_{i}$ and $\tau$ measurements [1-6]. It is the large increase in both $G_{i}$ and $\tau$ that causes - along with surface reaction weakening of the fibres - the weak, brittle behaviour of these materials after heat treatments in air between $600^{\circ} \mathrm{C}-800^{\circ} \mathrm{C}$.

This class of CMC must therefore be ruled out as a possible component material for regular use at temperatures in the $600^{\circ} \mathrm{C}-800^{\circ} \mathrm{C}$ range in oxidising environments, if it has to operate at stresses above its matrix cracking stress. However, oxidation of carbon in air is possible at approximately $400^{\circ} \mathrm{C}$ and higher. Therefore the removal of the carbon interface and associated changes in interfacial mechanical properties should be expected at this low temperature. The work reported here has concentrated on the effects on interfacial properties of oxidative heat treatments at temperatures lower than $600^{\circ} \mathrm{C}$ on CAS/Nicalon, cross-ply reinforced, glass ceramic matrix composite (manufactured by Corning, USA).

\section{INTERFACIAL MICROMECHANICAL PROPERTIES}

The fibre push-down test has previously been used to measure the interfacial micromechanical properties of CAS/Nicalon, after a range of heat treatments in air that focused on temperatures higher than $600^{\circ} \mathrm{C}[1-4]$. These were performed using a prototype SEM based microindentation system with a blunted conical diamond tip [7]. In the present study, a commercial nanoindentation system [8] has been used to study the interface behaviour of CAS/Nicalon after heat treatments in the range $375^{\circ} \mathrm{C}$ to $600^{\circ} \mathrm{C}$ for 100 hours in air. Unlike the previous work, the diamond tip used to indent the fibres had a standard Berkovich geometry. There has been no difference noted between measurements made with the two indentation systems on the as-fabricated CAS/Nicalon material both systems gave interfacial properties in the range $G_{i}=8 \pm 3 \mathrm{Jm}^{-2}$ and $\tau=25 \pm 5 \mathrm{MPa}$ (mean \pm standard deviation, using the original analytical model of Marshall and Oliver [9]).

Heat treated specimens were prepared by placing a bar of composite material $(12 \mathrm{~mm} \times 3 \mathrm{~mm} \times$ $3 \mathrm{~mm}$ ) on an alumina support, in a furnace with an air environment already at the required temperature. The specimens were then taken out and allowed to air cool after 100 hours in the furnace. After cooling they were cut in half and $5 \mathrm{~mm}$ deep specimens were mounted with the fibres in the outer most ply of the material aligned in the same direction as the indentor axis, and polished to a $1 \mu \mathrm{m}$ finish. The details of the fibre push-down test have been detailed elsewhere [14,9 ]. In the current work, at least 40 fibres were tested in each sample. Only fibres greater than $15 \mu \mathrm{m}$ diameter were pushed as a significant dependence of $\tau$ with fibre diameter has previously been observed with smaller fibres, that is probably due to radial Poisson expansion of the fibre 
under the compressive loading [10]. In each of the current tests, after the initial loading and unloading cycle, two more reloading / unloading cycles were performed without the indentor tip losing contact with the specimen surface.

For this series of experiments, the original model of Marshall and Oliver [9] was used to determine $G_{i}$ and $\tau$ from the applied load vs. fibre displacement data recorded during fibre pushing. It ignores both residual stresses and any Poisson radial expansion of the fibre whilst it is being pushed. However, as a qualitative measure it is very simple to apply with confidence as, in the vast majority of cases, the recorded data displays the straight line relationship predicted for the initial loading cycle on a p. of of the square of applied load vs. fibre displacement. In the case of CAS/Nicalon, $G_{i}$ and $\tau$ are over estimated with this model [10].

Table 1. Interfacial micromechanical properties of heat treated CAS/Nicalon ( \pm standard deviation).

\begin{tabular}{ccc}
\hline Specimen & $\mathrm{G}_{\mathrm{i}}\left(\mathrm{Jm}^{-2}\right)$ & $\tau$ (MPa) \\
\hline As fabricated & $8 \pm 3$ & $25 \pm 5$ \\
$375^{\circ} \mathrm{C}, 100$ hours & $1.1 \pm 1.0$ & $40 \pm 14$ \\
$450^{\circ} \mathrm{C}, 100$ hours & $4.7 \pm 3.7$ & $144 \pm 63$ \\
$525^{\circ} \mathrm{C}, 100$ hours & $6.3 \pm 4.3$ & $177 \pm 54$ \\
$600^{\circ} \mathrm{C}, 100$ hours & $9.3 \pm 5.5$ & $193 \pm 57$ \\
\hline
\end{tabular}

Table 1 shows the recorded $G_{i}$ and $\tau$ for the as fabricated material and hèat treated specimens. These mean values with standard deviations are determined from the intercept on the load ${ }^{2}$ axis and gradient of the initial loading slope, respectively [9]. The mean properties for each specimen are plotted in figure 1 .

a)

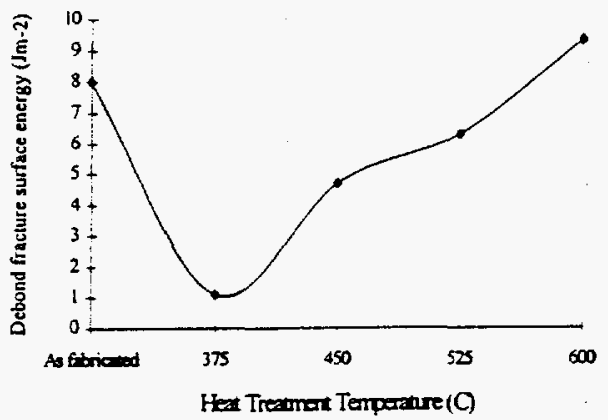

b)

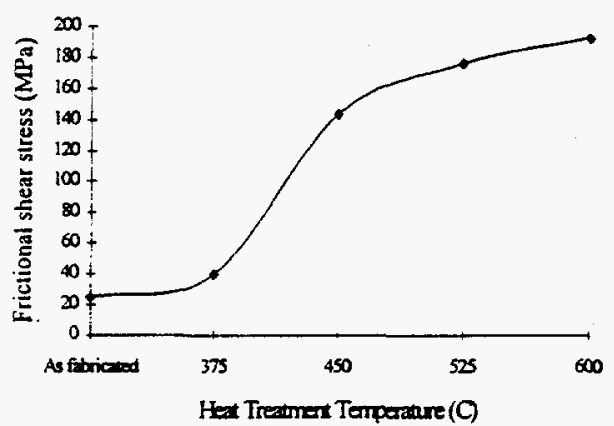

Figure 1 Changes in the mean interfacial properties of CAS/Nicalon after heat treatments in air, for 100 hours at the shown temperatures (a) debond fracture surface energy $G_{i}$. (b) frictional shear stress $\tau$. 
a) As fabricated

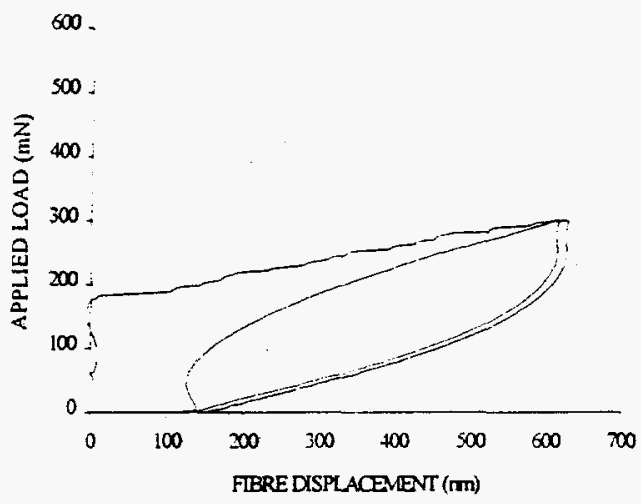

b) After 100 hours at $375^{\circ} \mathrm{C}$ in air

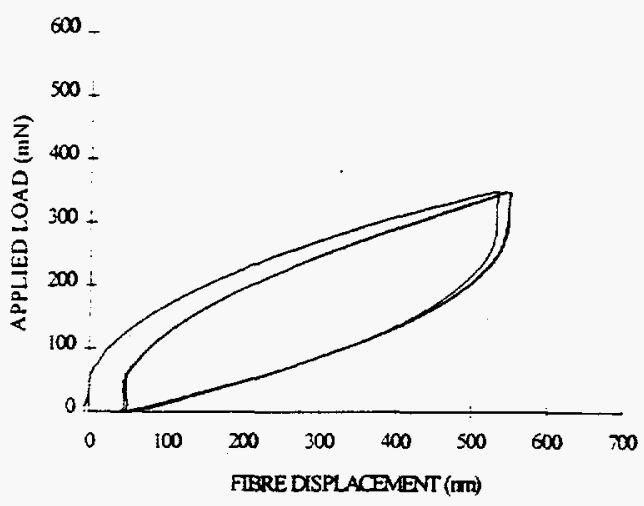

c) After 100 hours at $450^{\circ} \mathrm{C}$ in air

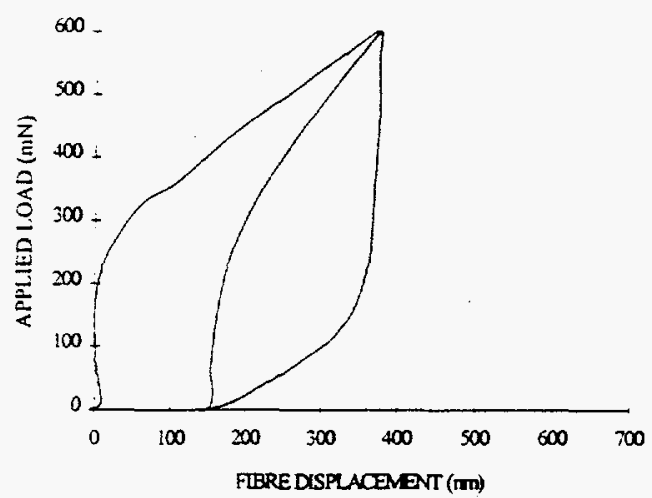

Figure 2. Typical Applied load vs. Fibre displacement traces recorded for the (a) as fabricated specimen, (b) the $375^{\circ} \mathrm{C}$ heat treated specimen and, (c) the $450^{\circ} \mathrm{C}$ treated specimen. One reload cycle is shown.

The changes in $G_{i}$ and $\tau$ compared to the as fabricated material are considerable. Typical applied load vs. fibre displacement curves for fibres tested in the as fabricated, $375^{\circ} \mathrm{C}$ and $450^{\circ} \mathrm{C}$ specimens are shown in figure 2 (a,b,c respectively). They are placed on the same scale axes to illustrate their different behaviours. The high debond fracture surface energy of the as-fabricated material is demonstrated by the high point of intercept with the load ${ }^{2}$ axis. The very low debond fracture surface energy for the $375^{\circ} \mathrm{C}$ specimen is, in the large majority of cases, the same on the second and third loading cycles as on the initial loading (see figure lb). Thus, it can be deduced that there is no "chemical" bonding at the interface. The low applied load required to initiate fibre movement on the initial loading cycle must be due to a static frictional shear stress and not a material fracture event. Increases in $\tau$ are illustrated by the steeper gradients in the loading segments of the indentation cycles in figure $2(b, c)$.

SEM studies of the fibres after the cyclic push-down tests were made. It was observed that the heat treated specimens had debris on the fibre surface, emanating from the interface. Figure 3 shows 
the typical appearance of fibres pushed in (a) the as fabricated material and (b) the $450^{\circ} \mathrm{C}$ treated material. The debris was present on all fibres pushed in all heat treated specimens but not in the as fabricated material. X-Ray Energy Dispersive Spectroscopy (EDS) was performed on the debris material but although the presence of calcium and aluminium was recorded, no definite decision could be made on its composition as the recorded spectra were dominated by the underlying Nicalon fibre. Back Scattered Electron (BSE) microscopy again showed possible signs of the debris containing other phases than that of the fibre, but again more surface sensitive analysis techniques are required to confidently characterise the debris.

a) As fabricated

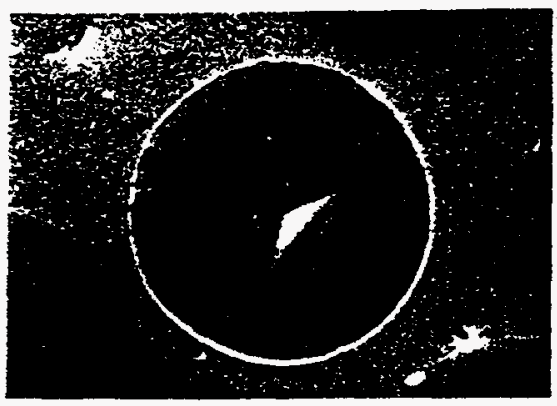

b) After $450^{\circ} \mathrm{C}$ heat treatment

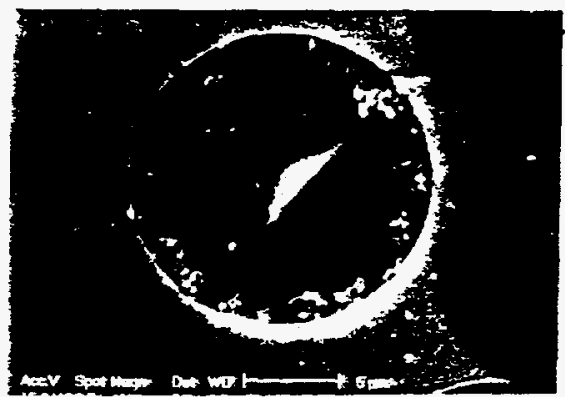

Figure 3. SEM micrographs indicating appearance of fibre surfaces after push-down tests with 3 loadreload cycles; (a) as fabricated specimen and. (b) $450^{\circ} \mathrm{C}$ heat treated specimen. Note the presence of debris on the second fibre due to the increased interfacial frictional shear stress $\tau$.

\section{MECHANICAL PROPERTIES}

Mechanical four-point flexure testing was carried out at room temperature. Test bar size was $50 \mathrm{~mm} \times 3.5 \mathrm{~mm} \times 2.5 \mathrm{~mm}$ and they were heat treated as before. Figure 4 shows the typical data obtained form the tests for the specimens subjected to the different heat treatment temperatures. Figure 4(a) shows the behaviour of the as-fabricated material is tough, illustrating typical composite failure. Of particular note is the 'tail' that is present after the ultimate strength where fibre pull out contributes significantly to the work of fracture. For the $375^{\circ} \mathrm{C}$ treated material, the failure behaviour is very similar to that of the as-fabricated material. It is tough and displays the fibre pull out 'tail'.

After the $450^{\circ} \mathrm{C}$ heat treatment, a dramatic change in mechanical properties is observed. The material retains a high ultimate strength but fails in a brittle manner. It displays the toughening mechanism of matrix cracking (occurring at an approximate load of $25 \mathrm{~N}$, see figure $4(\mathrm{c})$ )), but at the ultimate strength it fails catastrophically, with no fibre pull out present and hence no 'tail' on the load vs. deflection curve that would contribute to the work of fracture. At $600^{\circ} \mathrm{C}$ the mechanical properties deteriorate significantly with both brittle and weak behaviour displayed (figure $4(d)$ ). 
a) As fabricated

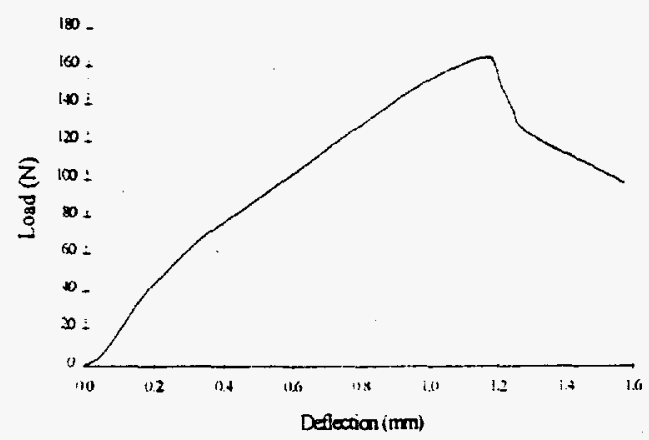

c) $450^{\circ} \mathrm{C}$ heat treated

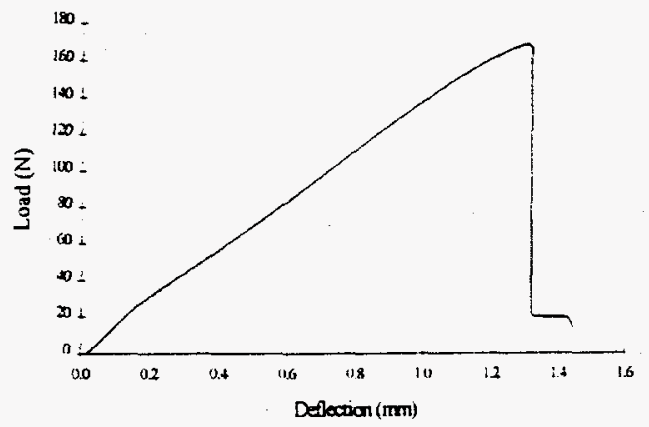

b) $375^{\circ} \mathrm{C}$ heat treated

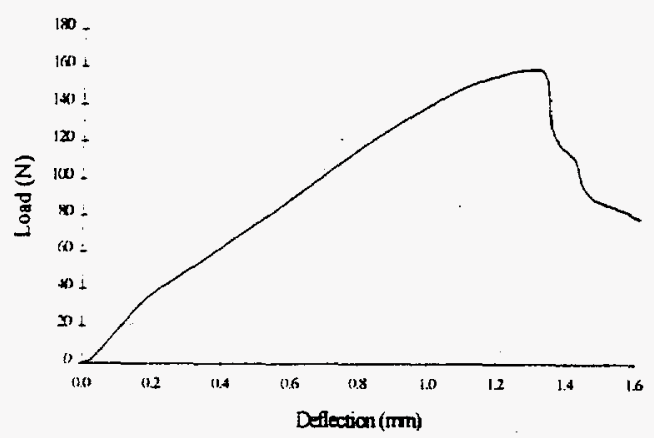

d) $600^{\circ} \mathrm{C}$ heat treated

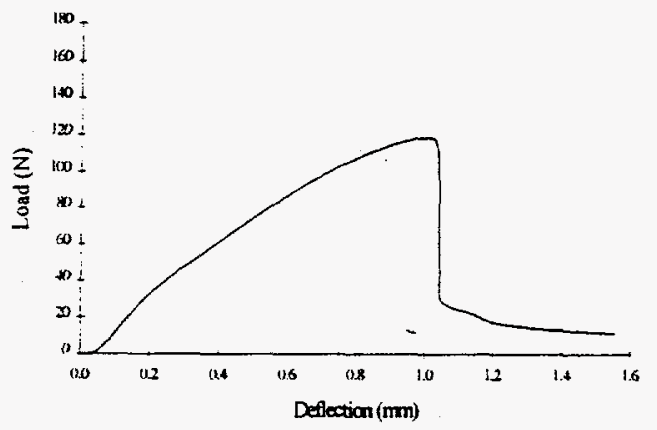

Figure 4. Load vs. deflection data for four point flexure testing of CAS/Nicalon a) as fabricated, b) after 100 hours at $375^{\circ} \mathrm{C}$ in air, c) after 100 hours at $450^{\circ} \mathrm{C}$ in air and d) after 100 hours at $600^{\circ} \mathrm{C}$ in air.

\section{DISCUSSION AND CONCLUSIONS}

It is evident that oxidation of the in situ formed carbon interface in CAS/Nicalon occurs at temperatures as low as $375^{\circ} \mathrm{C}$, as significant changes in the interfacial micromechanical response can be observed after heat treatments of 100 hours in air at this temperature. Compared to the as fabricated material, the interface present after this heat treatment has a very low debond fracture surface energy $G_{i}=1.1 \bullet 1.0 \mathrm{Jm}^{-2}$. The majority of fibres were not chemically bonded to the matrix and, in fibre push-down tests, required an applied load to overcome a static frictional shear stress before they were displaced. This is shown in figure $2(a, b)$ where the fibres in the asfabricated material required a much lower applied load to initiate sliding on reloading cycles than on the initial loading cycle (i.e. there was a debond event on initial loading only), but for the $375^{\circ} \mathrm{C}$ heat treated material, the same load was required on reload as on initial load - indicating that there was no interface fracture on initial loading, but a static frictional shear stress which was the same on subsequent reload. The measured increase in frictional shear stress (from $\tau=25 \mathrm{MPa}$ for the as fabricated material to $40 \mathrm{MPa}$ for the $375^{\circ} \mathrm{C}$ specimen) also confirms changes occurring to the lubricating carbon interfacial layer at this temperature. Scanning Auger Microscopy (SAM) 
has demonstrated that the carbon interfacial layer in this specimen is only $2-3 \mathrm{~nm}$ thick in comparison to the $20-40 \mathrm{~nm}$ wide carbon layer in the as fabricated material. Thus, it seems that the decrease in debond fracture surface energy and increase in frictional shear stress of the interface after heat treatments of 100 hours in air at $375^{\circ} \mathrm{C}$ are caused by the almost total removal of the lubricating carbon interface. Evidence of wear at the interface was also produced after the fibres were subjected to cyclic loading.

At $450^{\circ} \mathrm{C}$ the interfacial properties change again. The measured debond fracture surface energy increases from that at $375^{\circ} \mathrm{C}$ (figure 1(a)) but the frictional shear stress increases dramatically to $\tau=144 \pm 63 \mathrm{MPa}$ (figure $1(\mathrm{~b})$ ). This is accompanied by a transition in the mechanical behaviour of the composite as a whole from displaying tough to displaying brittle failure (figure 4(c)). SAM has confirmed that there is no carbon layer left at the interface in this material. It has been oxidised via 'pipeline' diffusion of oxygen along the interface, following reactions (1) and (2). The total lack of any lubricating carbon interface accounts for the dramatic increase in frictional shear stress that is recorded during fibre push-down tests. Further confirmation of this is the presence of wear debris on the surface of the fibres after they have been subjected to two reloading cycles (figure 3). This wear is not present on fibres subjected to the same test in the as fabricated material i.e. the carbon interface reduces frictional shear stress and therefore reduces wear at the interface. The high debond fracture surface energy measured for this material is believed to be due to a large increase in the static frictional shear stress required to be overcome before fibre sliding can occur. In figure 2(c) it is observed that fibre sliding does not occur on initial loading until $200 \mathrm{mN}$. On reloading, it again does not move significantly until a load of approximately $200 \mathrm{mN}$ is applied. This would suggest there is no interfacial chemical bond present after this heat treatment. The very large $\tau$ and high $G_{i}$ are caused by the compressive residual stresses across the interface (due to fibre and matrix coefficient of thermal expansion mismatch), and the absence of the lubricating interfacial layer.

The effect that the high $\tau$ has on mechanical properties is directly observed in the flexure tests of the $450^{\circ} \mathrm{C}$ material. The brittle behaviour evidenced by lack of fibre pull out is due directly to the very large $\tau$ causing fibre failures to occur very close to the matrix crack plane.

The behaviours for $525^{\circ} \mathrm{C}$ and $600^{\circ} \mathrm{C}$ are very similar to that of $450^{\circ} \mathrm{C}$ with increases in $\mathrm{G}_{\mathrm{i}}$ and $\tau$ possibly due to higher residual stresses across the interface due to cooling from the higher heat treatment temperature. At $600^{\circ} \mathrm{C}$ the nature of interfacial bonding is expected to begin to be dominated by silica bridging. Further analysis of the loading and reloading fibre push data is required to confirm this.

In summary, modification of interfacial micromechanical properties has been observed after heat treatments for 100 hours in air at temperatures between $375^{\circ} \mathrm{C}$ and $600^{\circ} \mathrm{C}$. Changes in $\mathrm{G}_{i}$ and $\tau$ over this temperature range have been attributed to removal of the lubricating, carbon interface by oxidation and the 'clamping' of the matrix onto the fibre due to residual stresses. The difference between chemical bonding and static frictional shear stress can be observed by cyclic loading of fibres during the fibre push-down test. 


\section{ACKNOWLEDGEMENTS}

AMD wishes to thank the Director General XII of the Commission of the European Union for provision of a grant under the Human Capital and Mobility of Researchers programme. KPP wishes to acknowledge the support of the ORNL Postdoctoral Research Program administered by the Oak Ridge Institute for Science and Technology.

\section{REFERENCES}

[1] M.H.Lewis, A.M. Daniel, A. Chamberlain, M.W.Pharaoh, M.G.Cain. Microstructureproperty relationships in silicate matrix composites. J.Microscopy 169, 2, 109-118, (1993).

[2] A.M. Daniel, M.H.Lewis. Measurement of the Interfacial Micromechanics of Fibre Reinforced Ceramic Matrix Composites. Ceram. Eng. Sci. Proc. Vol. 14, 7-8 131-138, (1993).

[3] K.P.Plucknett, S.Sutherland, A. M. Daniel, R.L.Cain, G.West, D.M.R.Taplin, M.H.Lewis. Environmental ageing effects in a silicon carbide fibre-reinforced glassceramic matrix composite J.Microscopy 177, 3, 251-263, (1995).

[4] A. M. Daniel. Interfacial properties of fibre reinforced ceramic matrix composites. PhD Thesis, University of Warwick, UK. November 1994.

[5] K.P.Plucknett, H.-T.Lin, D.N.Braski, P.F.Becher. Environmental aging degradation in continuous fiber ceramic composites. Proc. ICCM-10, Vol. IV,803-810, (1995).

[6] M.W.Pharaoh, A.M. Daniel, M.H.Lewis. Stability of interfaces in calcium aluminosilicate matrix/Nicalon SiC fibre composites. J.Mat Sci Lett. 12, 998-1001, (1993).

[7] A.M. Daniel, S.T. Smith, M.H. Lewis. A scanning electron microscope based microindentation system. Rev.Sci.Instrum. 65, 3, 632-638, (1994).

[8] Nanolndenter II, NanoInstruments, 1001 Larson Drive, Oak Ridge, TN, USA.

[9] D.B.Marshall, W.C. Oliver. Measurement of interfacial mechanical properties in fibre reinforced ceramic composites. J.Am. Ceram. Soc. 70, 8 542-548, (1987).

[10] A.M. Daniel, M.R. Elizalde, J. Janczak. Residual stress and poisson expansion effects on the fibre-matrix interfacial properties measured in fibre push tests. Proceedings of the 20th Annual Conference on Advanced Ceramics and Composites, 7-11 Jan. 1996, Cocoa Beach, FL, USA.

Research sponsored by the U.S. Department of Energy, Division of Materials Sciences, Office of Basic Energy Sciences, under contract DE-ACO5960R22464 with Lockheed Martin Energy Research Corp.

\section{DISCLAIMER}

This report was prepared as an account of work sponsored by an agency of the United States Government. Neither the United States Government nor any agency thereof, nor any of their employees, makes any warranty, express or implied, or assumes any legal liability or responsibility for the accuracy, completeness, or usefulness of any information, apparatus, product, or process disclosed, or represents that its use would not infringe privately owned rights. Reference herein to any specific commercial product, process, or service by trade name, trademark, manufacturer, or otherwise does not necessarily constitute or imply its endorsement, recommendation, or favoring by the United States Government or any agency thereof. The views and opinions of authors expressed herein do not necessarily state or reflect those of the United States Government or any agency thereof. 